\title{
Prevalência e perfil de resistência da Escherichia coli isolada de infecções do trato
}

\section{urinário}

Prevalence and resistance profile of Escherichia coli isolated from urinary tract infections

Perfil de prevalencia y resistencia de Escherichia coli aislada de infecciones del tracto urinario

Recebido: 02/12/2021 | Revisado: 10/12/2021 | Aceito: 15/12/2021 | Publicado: 01/01/2022

Edinelson de Sousa Barbosa

ORCID: https://orcid.org/0000-0002-2575-7531

Faculdade Cosmopolita, Brasil

E-mail: edinelsonsb30@gmail.com

Clyvia de Jesus Leite

ORCID: https://orcid.org/0000-0002-1087-0048

Faculdade Cosmopolita, Brasil

E-mail: clyvialeite@gmail.com

Daiane do Carmo Mendes

ORCID: https://orcid.org/0000-0002-0345-2403

Faculdade Cosmopolita, Brasil

E-mail: dcmendes1@gmail.com

Heliton Patrick Cordovil Brígido

ORCID: https://orcid.org/0000-0002-8472-2179

Universidade Federal do Pará, Brasil

E-mail: helitombrigido@gmail.com

\begin{abstract}
Resumo
O presente estudo avaliou a prevalência e o perfil de resistência da E. coli isolada de infecções do trato urinário. Trata-se de uma revisão integrativa, realizada em diferentes bases de dados: Portal de Periódicos CAPES, Biblioteca Virtual em Saúde, Biblioteca Nacional de Medicina e Biblioteca Eletrônica Cientifica Online, de artigos publicados nos últimos 5 anos (2016-2020), utilizando os seguintes descritores: E. coli, infecção urinária e resistência. Foram coletados 86 para triagem, entretanto, adotando-se os critérios de inclusão e exclusão, foram selecionados 6 artigos. Os estudos mostraram que a $E$. coli é o patógeno mais comum em ITUs, sua prevalência na maioria dos estudos foi maior que 50\%. Além disso, em todos os estudos, o sexo feminino foi mais acometido. Quanto ao perfil de suscetibilidade da $E$. coli, verificou-se que que as cepas mostraram um perfil de resistência alto frente aos fármacos $\beta$ lactâmicos (Ampicilina e Amoxicilina) e sensibilidade frente aos fármacos da classe das fluoroquinolonas e aminoglicosídeos. A ocorrência dos patógenos causadores de infecção urinária varia geograficamente, assim, como o seu perfil de susceptibilidade, portanto, é necessário a realização de estudos que avaliem tal cenário afim de se evitar o uso indiscriminado de antimicrobianos.
\end{abstract}

Palavras-chave: Infecção urinária; Escherichia coli; Resistência.

\begin{abstract}
The present study evaluated the prevalence and resistance profile of $E$. coli isolated from urinary tract infections. Methodology: This is an integrative review, carried out in different databases: CAPES Journal Portal, Virtual Health Library, National Library of Medicine and Online Scientific Electronic Library, of articles published in the last 5 years (2016-2020), using the following descriptors: E. coli, urinary infection and resistance. 86 were collected for screening, however, adopting the inclusion and exclusion criteria, 6 articles were selected. Studies have shown that $E$. coli is the most common pathogen in UTIs, its prevalence in most studies being greater than $50 \%$. Furthermore, in all studies, females were more affected. As for the susceptibility profile of $E$. coli, it was found that the strains showed a high resistance profile against $\beta$-lactam drugs (Ampicillin and Amoxicillin) and sensitivity against drugs of the class of fluoroquinolones and aminoglycosides. The occurrence of pathogens that cause urinary tract infections vary geographically, as does their susceptibility profile, therefore, it is necessary to carry out studies that assess this scenario in order to avoid the indiscriminate use of antimicrobials.
\end{abstract}

Keywords: Urinary infection; Escherichia coli; Resistance.

\section{Resumen}

El presente estudio evaluó el perfil de prevalencia y resistencia de E. coli aislada de infecciones del tracto urinario. Se trata de una revisión integradora, realizada en diferentes bases de datos: Portal de Revistas CAPES, Biblioteca Virtual en Salud, Biblioteca Nacional de Medicina y Biblioteca Electrónica Científica en Línea, de artículos publicados en los últimos 5 años (2016-2020), utilizando los siguientes descriptores: E. coli, infección urinaria y resistencia. Se 
recogieron 86 para cribado, sin embargo, adoptando los criterios de inclusión y exclusión, se seleccionaron 6 artículos. Los estudios han demostrado que E. coli es el patógeno más común en las infecciones urinarias, y su prevalencia en la mayoría de los estudios es superior al 50\%. Además, en todos los estudios, las mujeres se vieron más afectadas. En cuanto al perfil de susceptibilidad de E. coli, se encontró que las cepas mostraban un alto perfil de resistencia frente a fármacos $\beta$-lactámicos (Ampicilina y Amoxicilina) y sensibilidad frente a fármacos de la clase de fluoroquinolonas y aminoglucósidos. La ocurrencia de patógenos causantes Las infecciones del tracto urinario varían geográficamente, al igual que su perfil de susceptibilidad, por lo que es necesario realizar estudios que evalúen este escenario para evitar el uso indiscriminado de antimicrobianos.

Palabras clave: Infección urinaria; Escherichia coli; Resistencia.

\section{Introdução}

As infecções do trato urinário (ITUs) estão entre as infecções microbianas mais comuns, afetando 150 milhões de pessoas em todo o mundo a cada ano (Kumar et al., 2015; Grabe et al., 2015). Embora tanto homens quanto mulheres possam ser infectados, as ITUs são tradicionalmente consideradas uma doença mais prevalente em mulheres, entre as quais $50 \%$ serão afetadas ao longo de sua vida. Aproximadamente 25\% das mulheres que apresentam um primeiro episódio de cistite bacteriana passam a sofrer ITU recorrente dentro de 6 meses, algumas tendo 6 ou mais infecções no ano após o episódio inicial (Haddad, 2015).

A ITU ocorre quando a flora normal da área periuretral é substituída por bactérias uropatogênicas, que ascendem pelo trato urinário. A infecção ocorre devido a fatores ligados à virulência da bactéria e susceptibilidade do hospedeiro, que permitem melhor aderência e colonização dos microrganismos. O principal patógeno envolvido na ITU em mulheres é a Escherichia coli, um bacilo Gram-negativo da família das enterobactérias, que é responsável por cerca de $80 \%$ de todos os episódios de infecção (Trabulsi et al., 2008). Outros patógenos significativos incluem Enterobactérias, principalmente Klebsiella pneumoniae e Proteus mirabilis além de Staphylococcus saprophyticus, Enterococcus faecalis, Pseudomonas aeruginosa e Candida sp. cada um desses representando 4\% de todos os episódios de cistite aguda (Grabe et al., 2015).

Segundo Vieira e et al., (2017), há um aumento preocupante na incidência da resistência bacteriana aos antimicrobianos de amplo espectro. Neste contexto, o aumento na resistência bacteriana à antibióticos é considerado um sério problema de saúde pública, não somente no ambiente hospitalar, mas também para pacientes não-hospitalizados com ITU. Assim, medidas efetivas, como o uso racional de antimicrobianos, precisam ser efetivadas de modo a minimizar a evolução da resistência bacteriana aos antimicrobianos (WHO, 2015).

As bactérias utilizam inúmeros mecanismos de resistência contra a ação de antibióticos. Os mecanismos de resistência antimicrobiana se enquadram em quatro categorias principais: limitação da absorção de um medicamento; modificar um alvo de droga; inativar um medicamento; efluxo de droga ativa. A resistência intrínseca pode limitar a captação, a inativação e o efluxo de drogas; os mecanismos de resistência adquiridos usados podem ser modificação do alvo da droga, inativação da droga e efluxo da droga (Tenover, 2006; Liu et al., 2020). Por causa das diferenças na estrutura, há uma variação nos tipos de mecanismos usados por bactérias Gram negativas versus bactérias Gram positivas. As bactérias Gram negativas usam todos os quatro mecanismos principais, enquanto as bactérias Gram positivas usam menos comumente a limitação da absorção de uma droga e não têm a capacidade para certos tipos de mecanismos de efluxo de drogas (Mahon et al., 2014; Deak et al., 2016).

No caso da E. coli, particularmente aqueles isolados de infecções do trato urinário, um dos principais mecanismos de resistência está relacionado com a produção de enzimas inativadoras, a exemplo das $\beta$-lactamases de espectro estendido (ESBL) e metal- $\beta$-lactamases e, como os próprios nomes dizem, têm espectro/potencial de degradação crescente e associado a cada classe ou subclasse de beta-lactâmico (Cabral, 2011). Essas $\beta$-lactamases tem atividade restrita de degradação, geralmente, direcionada para as penicilinas lábeis (ex.: penicilina, amoxicilina) (Andrade et al., 2016).

A Organização Mundial de Saúde (OMS) levantou os principais fatores que influenciam no desenvolvimento de 
resistência, dentre eles estão: prescrição em excesso; omissão da prescrição; doses e duração inapropriadas; seleção inadequada; gastos e riscos desnecessários (WHO, 2015). Além disso, outros estudos mostram que outros fatores podem influenciar de forma direta para o aumento de resistência como: acesso facilitado ao consumo de antibióticos e automedicação; erro diagnóstico das infecções; ausência de comissão quanto ao uso de antimicrobianos no ambiente hospitalar; crença que o tratamento com antimicrobianos de amplo espectro seja mais eficaz, quando aplicado na terapêutica; desconhecimentos sobre administração de antibióticos, incluindo doses, diluições e intervalos; além das reações adversas (Roriz et al., 2010).

Neste cenário, a resistência dos patógenos frente aos fármacos antimicrobianos é um grave problema de saúde pública, acarretando dificuldades no controle de infecções e contribuí para o aumento dos custos do sistema de saúde. Além disso, a ocorrência dos microrganismos causadores de ITU varia geograficamente, assim, como o seu perfil de susceptibilidade. Portanto, o presente trabalho teve como objetivo, através de uma revisão integrativa, avaliar a prevalência e o perfil de resistência da $E$. coli isolados de ITUs.

\section{Metodologia}

Para realização desta revisão integrativa, foi desenvolvida uma pesquisa de seleção de artigos científicos disponíveis nas seguintes plataformas de buscas: Portal de Periódicos CAPES (PPC), Biblioteca Virtual em Saúde (BVS), Biblioteca Nacional de Medicina (PUBMED) e Biblioteca Eletrônica Cientifica Online (SCIELO), publicados nos últimos 5 anos (20162020). O período de busca foi entre janeiro à março de 2021, sendo adotados como critérios de inclusão apenas artigos em português, inglês e espanhol, estudos que foram realizados no Brasil, bem como adequação do título ao tema analisado, e resumo compatível. Em relação aos critérios de exclusão, foram adotados os seguintes: artigos que não abordaram o tema de estudo, artigos de outros idiomas, estudos realizados em outros países, artigos que que não avaliaram o perfil de prevalência e de suscetibilidade da E. coli, artigos não disponíveis na íntegra, duplicados, e artigos que não foram analisados por especialistas.

Os descritores representativos para a pesquisa dos artigos nas plataformas de busca foram: E. coli, infecção urinária e resistência. Inicialmente, foram coletados 86 para triagem ( $\mathrm{PP}=26, \mathrm{BVS}=22, \mathrm{PUBMED}=20$ e SCIELO = 18), entretanto, deste total, após análise do título e resumo, foram excluídos 80 artigos, sendo selecionados somente 6 artigos para leitura na íntegra e provável inclusão na revisão integrativa.

A seleção dos artigos foi baseada no título e resumo, sendo realizada por três revisores que levaram em consideração os critérios de inclusão e exclusão da revisão. Em casos de divergências na análise de seleção, foi consultado um quarto revisor para assegurar o cumprimento dos requisitos do estudo.

\section{Resultados e Discussão}

No Quadro 1 estão dispostos os títulos dos 6 artigos que compõem a amostra desta pesquisa. 
Quadro 1: Artigos com a temática da prevalência e perfil de resistência de Escherichia coli isolados de infecções do trato urinário selecionados para a pesquisa (2016 - 2020).

\begin{tabular}{|c|c|c|c|}
\hline $\mathbf{N}^{\circ}$ & $\begin{array}{l}\text { Título do Artigo } \\
\end{array}$ & Periódico & Referência \\
\hline 1 & $\begin{array}{l}\text { Infecções comunitárias do trato urinário: prevalência e } \\
\text { susceptibilidade aos antimicrobianos na cidade de } \\
\text { Florianópolis. }\end{array}$ & $\begin{array}{l}\text { Revista Brasileira de Medicina de } \\
\text { Familia e Comunidade. }\end{array}$ & Alves, et al. (2016). \\
\hline 2 & $\begin{array}{l}\text { Etiologia e perfil de resistência bacteriana em uroculturas de } \\
\text { pacientes atendidos em um hospital público de Macapá-Amapá, } \\
\text { Brasil. Um estudo transversal. }\end{array}$ & Revista Diagnóstico e Tratamento & $\begin{array}{l}\text { Santos Porcy e } \\
\text { Oliveira Menezes, } \\
\text { (2019). }\end{array}$ \\
\hline 3 & $\begin{array}{l}\text { Resistencia antimicrobiana de la Escherichia coli en pacientes } \\
\text { con infección del tracto urinario }\end{array}$ & Revista Informacíon Científica. & Expósito et al., (2019). \\
\hline 4 & $\begin{array}{l}\text { Evolução da resistência bacteriana em infecção comunitária do } \\
\text { trato urinário em idosos. }\end{array}$ & $\begin{array}{l}\text { Revista de epidemiologia e } \\
\text { Controle de Infecção. }\end{array}$ & Póvoa et al., (2019). \\
\hline 5 & $\begin{array}{l}\text { Antibiotic Resistance Patterns of Urinary Tract Infections in a } \\
\text { Northeastern. }\end{array}$ & $\begin{array}{l}\text { Revista do Instituto de Medicina } \\
\text { Tropical de São Paulo. } \\
\end{array}$ & Cunha et al., (2016). \\
\hline 6 & $\begin{array}{l}\text { Perfil de resistência de agentes de infecção urinária em crianças } \\
\text { internadas em um hospital de pediatria em Belém do Pará. }\end{array}$ & $\begin{array}{l}\text { Brazilian Journal } \\
\text { of Health Review. }\end{array}$ & Brígido et al., (2020). \\
\hline
\end{tabular}

Fonte: Barbosa et al., (2021).

Todos os 6 artigos apresentaram como maior causador de infecção urinária a E. coli. A prevalência e o perfil de suscetibilidade de E. coli dos artigos utilizados no presente estudo estão destacados no Quadro 2.

Quadro 2: Prevalência e perfil de resistência de Escherichia coli isolados de infecções do trato urinário.

\begin{tabular}{|c|c|c|c|c|c|c|c|}
\hline \multirow[t]{3}{*}{ Artigos } & \multirow{3}{*}{$\begin{array}{l}\text { Amostras } \\
\text { avaliadas }\end{array}$} & \multirow{3}{*}{$\begin{array}{l}\text { Amostras } \\
\text { positivas }\end{array}$} & \multirow{3}{*}{$\begin{array}{l}\text { Prevalência } \\
\text { E. coli }(\%)\end{array}$} & \multicolumn{4}{|c|}{ Perfil de Suscetibilidade } \\
\hline & & & & \multicolumn{2}{|c|}{ Resistência } & \multicolumn{2}{|l|}{ Sensibilidade } \\
\hline & & & & Fármaco & $(\%)$ & Fármaco & $(\%)$ \\
\hline $\begin{array}{l}\text { Alves, et al. } \\
\text { (2016). }\end{array}$ & 4.603 & 1.035 & 77,1 & $\begin{array}{c}\text { Ampicilina } \\
\text { Cefalotina } \\
\text { Sulfametoxazol/Trim. } \\
\text { Ácido Nalidíxico } \\
\text { Amoxicilina/Clav. }\end{array}$ & $\begin{array}{l}55,8 \\
55,3 \\
31,7 \\
31,5 \\
33,1\end{array}$ & $\begin{array}{l}\text { Gentamicina } \\
\text { Nitrofurantoína } \\
\text { Norfloxacino } \\
\text { Ciprofloxacino }\end{array}$ & $\begin{array}{l}92,3 \\
85,9 \\
77,9 \\
77,2\end{array}$ \\
\hline $\begin{array}{c}\text { Santos Porcy e } \\
\text { Oliveira } \\
\text { Menezes, (2019). }\end{array}$ & 2.078 & 289 & 50,4 & $\begin{array}{c}\text { Amicacina } \\
\text { Norfloxacino } \\
\text { Ciprofloxacino } \\
\text { Meropenem } \\
\end{array}$ & $\begin{array}{c}63,4 \\
63 \\
61 \\
37 \\
\end{array}$ & Meropeném & 63 \\
\hline $\begin{array}{l}\text { Expósito et al., } \\
\text { (2019). }\end{array}$ & 567 & 341 & 60,1 & $\begin{array}{l}\text { Amoxicilina } \\
\text { Ampicilina } \\
\text { Azitromicina }\end{array}$ & $\begin{array}{l}61,6 \\
61,6 \\
54,5\end{array}$ & $\begin{array}{c}\text { Nitrofurantoína } \\
\text { Sulfametoxazol/Trim } \\
\text { Ácido Nalidíxico }\end{array}$ & $\begin{array}{l}92,9 \\
75,0 \\
71,4\end{array}$ \\
\hline $\begin{array}{l}\text { Póvoa et al., } \\
\text { (2019). }\end{array}$ & 3.388 & 2.563 & 75,65 & $\begin{array}{c}\text { Sulfonamida } \\
\text { Ciprofloxacino }\end{array}$ & $\begin{array}{l}40,5 \\
35,0\end{array}$ & $\begin{array}{l}\text { Ciprofloxacino } \\
\text { Sulfonamida }\end{array}$ & $\begin{array}{c}65 \\
59,5\end{array}$ \\
\hline $\begin{array}{c}\text { Cunha et al., } \\
\text { (2016). }\end{array}$ & 1.082 & 653 & 60,4 & $\begin{array}{c}\text { Sulfametoxazol/Trim. } \\
\text { Cefalotina } \\
\text { Ampicillina/Sulbactam } \\
\text { Ácido Nadixílico }\end{array}$ & $\begin{array}{l}57,2 \\
51,7 \\
50,4 \\
31,6\end{array}$ & $\begin{array}{c}\text { Amicacina } \\
\text { Nitrofurantoina } \\
\text { Ceftriaxona } \\
\text { Gentamicina } \\
\text { Cefepima } \\
\text { Amoxicillina/Clav. } \\
\text { Norfloxacino } \\
\text { Ciprofloxacino }\end{array}$ & $\begin{array}{l}94.1 \\
93,4 \\
92,2 \\
92,1 \\
90,8 \\
82,2 \\
79,6 \\
75,6\end{array}$ \\
\hline $\begin{array}{l}\text { Brígido et al., } \\
\text { (2020). }\end{array}$ & 2.222 & 1.555 & $38 \%$ & $\begin{array}{c}\text { Ampicilina } \\
\text { Ampicilina/Sulbactan }\end{array}$ & $\begin{array}{l}100 \\
78,6\end{array}$ & $\begin{array}{c}\text { Imipeném } \\
\text { Meropenem } \\
\text { Amicacina } \\
\text { Tigeciclina } \\
\text { Colistina } \\
\text { Ciprofloxacino } \\
\text { Gentamicina } \\
\text { Cefepima }\end{array}$ & $\begin{array}{l}100 \\
100 \\
100 \\
100 \\
100 \\
85,7 \\
78,6 \\
64,3 \\
\end{array}$ \\
\hline
\end{tabular}

Legenda: Trim. - Trimetoprima; Clav. - Clavunalato. Fonte: Barbosa et al., (2021). 
O estudo de Alves et al., (2016), apresentou a maior prevalência E. coli (77,10\%) dentre os outros estudos (Quadro 2). Verificou-se que as cepas apresentaram uma alta resistência aos antibióticos $\beta$-lactâmicos, principalmente a Ampicilina (52,8\%). Mesmo com um inibidor de $\beta$-lactamase (Clavunalato), as cepas ainda apresentaram uma alta resistência frente a Amoxicilina $(33,1 \%)$, mostrando que fármacos desta classe não devem ser utilizados no tratamento empírico. Por outro lado, para outros fármacos de outras classes, observou-se um baixo perfil de resistência para Nitrofurantoína, Gentamicina, Norfloxacino e Ciprofloxacino.

A produção de enzimas $\beta$-lactamases tem sido relatada como um importante mecanismo de resistência a antibióticos $\beta$-lactâmicos, hidrolisando o anel $\beta$-lactâmico pela quebra da ligação amídica perdendo assim, a capacidade de inibir a transpeptidase, sendo esta responsável pela síntese da parede celular (Rodrigues et a., 2020). Associado a isso, algumas enterobactérias, a exemplo da E. coli e Klebisiella, possuem a capacidade de produzir um tipo especial de $\beta$-lactamases, as ESBL. Esta é uma classe de enzimas codificadas por genes que podem estar presente em integrons, transposons, cassetes gênicos, contidos ou não em plasmídeos, e que apresenta a capacidade de hidrolisar e inativar uma grande variedade de antibióticos do grupo $\beta$-lactâmico, incluindo cefalosporinas de terceira geração, Penicilinas e Aztreonam (Carmo et al., 2018).

A alta sensibilidade da E. coli frente a Gentamicina, pode estar associado ao seu mecanismo de ação, que é diferente dos $\beta$-lactâmicos. Este fármaco pertence ao grupo dos Aminoglicosídeos, constituído por fármacos altamente efetivas contra bacilos Gram-negativos. São fármacos primariamente bactericidas por causarem alterações em proteínas sintetizadas pela bactéria, ao ligarem-se irreversivelmente aos ribossomos bacterianos. Podem também atuar de forma bacteriostática ao inibirem a síntese de proteínas (Bollela et al., 2018). No entanto, a sua principal limitação é a nefrotoxicidade e ototoxicidade, que devem sempre ser monitorizadas (Gonçalves, 2019). Assim, não são medicamentos utilizadas como tratamento de primeira escolha.

No estudo Santos, Porcy e Oliveira Menezes (2019), verificou-se que a prevalência das infecções urinárias causadas por E. coli foi de 50,4\% (Quadro 2), sendo 55\% das infecções positivas acometeram pacientes do gênero feminino. As cepas de E. coli se mostraram sensíveis ao Meropenem (63\%), e resistentes a Norfloxacino (63\%) e Ciprofloxacino $61 \%$.

Quando se trata de cistite não complicada, vários agentes antimicrobianos por via oral podem ser utilizados para seu tratamento. Nessas infecções, as fluoroquinolonas, a exemplo do Ciprofloxacino e Levofloxacino, podem ser prescritos empiricamente, pois, são altamente ativas contra bactérias da família das enterobactérias, e seu modo de ação envolve a inibição da síntese bacteriana de DNA ao bloquear a DNA-girase, com isso os mecanismos de resistência das bactérias são inibidos (Gomes, 2021). No entanto, o uso empírico das quinolonas deve ficar reservado apenas para casos mais graves, pelo grande risco de indução a resistência. O número crescente de resistência de $E$. coli às quinolonas tem sido amplamente observado na comunidade, dificultando a terapia empírica, percebe-se uma tendência de preferência dos médicos para utilização de agentes de amplo espectro (Alves et al., 2016).

A prevalência de E. coli no estudo de Expósito Boue et al., (2019), também foi elevada, como uma taxa de cerca de 60\% (Quadro 2). A taxa de resistência das cepas de E. coli neste estudo foi menor de 18\% para Cefalexina, Gentamicina, Canamicina, Ciprofloxacino e Nitrofurantoína. Já frente a outros antibióticos, como os $\beta$-lactâmicos (Ampicilina e Amoxicilina) e macrolídeos (Azitromicina) mostraram resistência de 61,6\% e 54,5\%, respectivamente. A sensibilidade de $E$. coli à Nitrofurantoína foi bem alta, de 92,9\%. No entanto, o estudo mostrou padrões de multirresistência em 57 cepas (16,6\%).

As cepas de E. coli estudadas apresentaram uma boa sensibilidade a Nitrofurantoína, o que traz evidências clínicas sobre a sua efetividade no tratamento das ITUs. Este fármaco é um agente antibacteriano específico do trato urinário. No interior das bactérias, o fármaco é reduzido por flavoproteínas bacterianas a intermediários reativos, que inativam as proteínas ribossomais e outras macromoléculas das bactérias sensíveis, o que inibe os processos bioquímicos vitais de síntese proteica, metabolismo aeróbio, síntese de DNA e RNA e síntese da parede celular bacteriana. Esse amplo mecanismo 
de ação pode explicar a ausência de resistência bacteriana adquirida à Nitrofurantoína (Rogers et al., 2014).

No estudo de Póvoa et al., (2019), a taxa de prevalência da E. coli correspondeu a 75,6\% (Quadro 2). A E. coli apresentou alta taxa de resistência à Sulfonamida (40,5\%) e Ciprofloxacino (35,0\%). Já no estudo de Cunha et al., (2016) a prevalência de $E$. coli foi menor (60,4\%; Quadro 2), porém, também foi elevada. Quanto ao perfil de suscetibilidade da E. coli, foi observado alta sensibilidade a Amicacina (94.1\%), Gentamicina (92.1\%), Amoxicillina/Clavulanato (82.2\%), Ceftriaxona (92.2\%), Cefepime (90.8\%), Ciprofloxacino (75.6\%), Norfloxacino (79.6\%) e Nitrofurantoina 93.4\%.

No estudo de Brígido et al., (2020), as bactérias da família das enterobactérias foram as mais prevalentes (70\%), sendo a $E$. coli o principal agente etiológico envolvido (38\%; Quadro 2). O sexo feminino foi o mais afetado pelas infecções (65\%). Quando ao perfil de suscetibilidade das cepas de E. coli, vericou-se 100\% de sensibilidade ao meropeném, Imipeném, Tigeciclina, Amicacina e Colistina. Para o Ciprofloxacino, 85,7\% das cepas foram sensíveis; 78,6\% à Gentamicina e 64,3\% à Cefepima. Quanto ao perfil de resistência, observou-se 100\% de resistência para Ampicilina, seguido de 78,6\% para Ampicilina/Sulbactam.

Observa-se preponderância importante de casos de ITUs no sexo feminino sobre o masculino, as mulheres apresentam susceptibilidade maior a esse tipo de infecção por fatores fisiológicos e anatômicos, como a proximidade da uretra com a vagina e ânus, além de outros fatores que aumentam o risco de ITU nas mulheres, como: frequência das relações sexuais, uso de métodos contraceptivos, gestações, menopausa, doenças congênitas e iatrogênicas, hábitos higiênicos, obesidade e condições socioeconômicas desfavoráveis, contribuindo para bactérias aeróbicas e anaeróbicas na instalação de infecções (Menezes et al., 2017).

Observamos que o perfil de suscetibilidade da E. coli varia de estudo para estudo. Vale ressaltar que, esses trabalhos foram realizados em regiões diferentes do país, por exemplo: Porcy e Oliveira Menezes (2019), realizaram em Macapá (AP), Alves et al., (2016) em Florianópolis (SC) e Brígido et al., (2020) em Belém (PA), demonstrando que além de fatores de adaptação a região também implica no perfil de suscetibilidade bacteriana. Outros fatores que influenciam para mutação bacteriana incluem o estado imunológico do paciente, o número de bactérias no sítio de infecção, o mecanismo de ação do antibiótico e o nível da droga que atinge a população bacteriana (Santos, 2004).

Um outro fator importante que têm contribuído para um aumento significativo da resistência bacteriana nos últimos anos é o uso ou "abuso" de tratamento empírico para infecções do trato urinário por clínicos gerais e especialistas (Concia et al., 2017). A decisão por tratamento empírico racional requer o conhecimento de quais são os principais agentes microbianos que podem estar envolvidos, além do perfil ou padrão de resistência aos antimicrobianos desses prováveis agentes etiológicos que, por sua vez, pode variar em cada região geográfica (Baerheim, 2015).

Neste cenário, para diminuir a taxa de resistência bacteriana, o diagnóstico de infecção urinária através do exame de urinocultura é de suma importância. Este exame identifica as espécies de microrganismos causadores da infecção e quantifica o crescimento bacteriano (Araujo et al., 2012). Além disso, também é necessário que seja realizado o antibiograma, uma vez que é um resultado bastante importante para terapia medicamentosa de pacientes com infecção urinária e diminui o uso irracional de antimicrobianos (Oliveira et al., 2016).

\section{Conclusão}

O presente estudo mostrou que a E. coli é a principal enterobactéria causadora de ITU, mostrando-se prevalente em todos os estudos avaliados. A maioria das cepas mostraram-se sensíveis ao Ciprofloxacino, Gentamicina, Meropenem e Nitrofurantoína; e resistentes aos $\beta$-lactâmicos (Ampicilina e Amoxicilina) e as Sulfas. Vale ressaltar que o perfil de suscetibilidade varia de acordo com cada região. Portanto, é importante o monitoramento periódico, a fim de obter informações 
atualizadas que reflitam peculiaridades regionais capazes de orientar a terapia antimicrobiana empírica e diminuir o uso indiscriminado de antimicrobianos.

\section{Agradecimentos}

A Faculdade Cosmopolita.

\section{Referências}

Alves, D. M., Edelweiss, M. K., \& Botelho, L. J. (2016). Infecções comunitárias do trato urinário: prevalência e susceptibilidade aos antimicrobianos na cidade de Florianópolis. Revista Brasileira de Medicina de Família e Comunidade, 11(38), 1-12.

Andrade, L.N.; Darini, A.L. C. Mecanismos de resistência bacteriana aos antibióticos. Divisão de MI - CM - FMRP-USP, 2016.

Baerheim, A. (2015). Empirical treatment of uncomplicated cystitis: Keep it simple.

Brígido, H. P. C., De Araújo, A. C. M., Rios, M. M., Boettger, B. C., Prado, L. P., Silva, C. M \& Almeida, M. D. G. C. (2020). Perfil de resistência de agentes de infecção urinária em crianças internadas em um hospital de pediatria em Belém do Pará. Brazilian Journal of Health Review, 3(4), 9808-9818.

Cabral, A. B. (2011). Caracterização genética de isolados clínicos de Klebsiella pneumoniae resistentes a antibióticos $\beta$-lactâmicos de última geração provenientes de Recife-PE (Master's thesis, Universidade Federal de Pernambuco).

Carmo, M. S. D., Marques, A. D. M., Gonçalves, L. H. B., Ferro, T. A. F., Monteiro, C. D. A., Bomfim, M. R. Q., ... \& Figueiredo, P. D. M. S. (2018). Detecção de betalactamases de espectro estendido (ESBL) em isolados de Escherichia coli uropatogênicas (UPECS) oriundos de pacientes da comunidade. Rev. patol. trop, 419-426.

Camou, T., Zunino, P., \& Hortal, M. (2017). Alarma por la resistencia a antimicrobianos: situación actual y desafíos. Revista Médica del Uruguay, 33(4), 104127.

Concia, E., Cornaglia, G., \& Novelli, A. (2017). Actual role of older oral antibiotics in the treatment of resistant urinary tract infections (UTIs). Journal of Chemotherapy, 29(sup1), 1-1.

Cunha, M. A., Assunção, G. L. M., Medeiros, I. M., \& Freitas, M. R. (2016). Antibiotic resistance patterns of urinary tract infections in a northeastern Brazilian capital. Revista do Instituto de Medicina Tropical de São Paulo, 58.

Deak D, Outterson K, Powers JH, et al. (2016) Avanços na luta contra bactérias multirresistentes? Uma revisão dos antibióticos aprovados pela Food and Drug Administration dos EUA, 2010-2015. Ann Intern Med 165: 363-372.

Expósito Boue, L. M., Bermellón Sánchez, S., Lescaille Garbey, L., Delgado Rondón, N., \& Aliaga Castellanos, I. (2019). Resistencia antimicrobiana de la Escherichia coli en pacientes con infección del tracto urinario. Revista Información Científica, 98(6), 755-764.

Gomes, G. D. F. (2021). Perfil microbiológico e protocolo de tratamento: prescrição empírica de antibióticos para infecção do trato urinário.

Gonçalves, M. D. (2019). Impacto clínico da monitorização farmacocinética de gentamicina, amicacina e vancomicina e a sua relação com a função renal (Doctoral dissertation).

Grabe, M., Bjerklund-Johansen, T. E., Botto, H., Çek, M., Naber, K. G., Tenke, P., \& Wagenlehner, F. (2015). Guidelines on urological infections. European association of urology, 182, 237-257.

Haddad, J. M. (2015). Manual de uroginecologia e cirurgia vaginal. São Paulo: Federação Brasileira das Associações de Ginecologia e Obstetrícia (FEBRASGO).

Kumar S, Dave A, Wolf B, Lerma EV (2015) Urinary tract infections http://dx.doi.org/10.1016/j.disamonth.2014.12.002.

Liu, M., Ma, J., Jia, W., \& Li, W. (2020). Antimicrobial resistance and molecular characterization of gene cassettes from class 1 integrons in Pseudomonas aeruginosa strains. Microbial Drug Resistance, 26(6), 670-676.

Mahon CR, Lehman DC, Manuselis G (2014) mecanismos do agente antimicrobiano de ação e resistência, In: Textbook of Diagnostic Microbiology, St. Louis: Saunders, 254-273.

Menezes RAO, Gomes MSM, Barbosa FHF, Maréco ML, Couto ÁARD. Prevalência de uropatógenos no laboratório de saúde pública de Macapá - AP entre 2009 e 2012. Rev Bras An Clin. 2017;49(1):80-7. doi: 10.21877/2448-3877.201600127.

Oliveira, R. A. D., Ribeiro, E. A., Gomes, M. C., Coelho, D. D., \& Tomich, G. M. (2016). Perfil de suscetibilidade de uropatógenos em gestantes atendidas em um hospital no sudeste do Estado do Pará, Brasil. Revista Pan-Amazônica de Saúde, 7(3), 43-50.

Póvoa, C. P., da Silva, R. C., dos Santos, K. C., Silva, A. C., Pereira, M. S., \& do Carmo Filho, J. R. (2019). Evolução da resistência bacteriana em infecção comunitária do trato urinário em idosos. Revista de Epidemiologia e Controle de Infecção, 9(1).

Rodrigues, R. C. E., da Silva, G. F., Junior, S. D., \& Albuquerque, P. M. (2020). Estudo da resistência bacteriana frente ao líquido da castanha de caju (Anacardium occidentale). Brazilian Journal of Health Review, 3(6), 18076-18094. 
Research, Society and Development, v. 11, n. 1, e0611124280, 2022

(CC BY 4.0) | ISSN 2525-3409 | DOI: http://dx.doi.org/10.33448/rsd-v11i1.24280

Rogers, R. G., Kammerer-Doak, D., Olsen, A., Thompson, P. K., Walters, M. D., Lukacz, E. S., \& Qualls, C. (2014). A randomized, double-blind, placebocontrolled comparison of the effect of nitrofurantoin monohydrate macrocrystals on the development of urinary tract infections after surgery for pelvic organ prolapse and/or stress urinary incontinence with suprapubic catheterization. American journal of obstetrics and gynecology, 191(1), 182-187.

Santos, M. J. A., Porcy, C., \& de Oliveira Menezes, R. A. (2019). Etiologia e perfil de resistência bacteriana em uroculturas de pacientes atendidos em um hospital público de Macapá-Amapá, Brasil. Um estudo transversal. Rev. Diagnóstico e tratamento, Vol. 24. Ed 4, 135.

Santos, N. D. Q. (2004). A resistência bacteriana no contexto da infecção hospitalar. Texto \& Contexto-Enfermagem, 13, 64-70.

Tenover, F. C. (2006). Mechanisms of antimicrobial resistance in bacteria. The American journal of medicine, 119(6), S3-S10.

Trabulsi, L. R., \& Alterthum, F. (2008). Microbiologia. In Microbiologia (pp. 718-718).

Vieira, P. N. \& Vieira, S. L. V. (2017). Uso irracional e resistência a antimicrobianos em hospitais. Arq. Cienc. Saúde UNIPAR. 21(3), $209-212$.

World Health Organization. (2015). Global antimicrobial resistance surveillance system: manual for early implementation. World Health Organization. 